\title{
$M$ moderated mediation model linking error management culture to organizational performance
}

\author{
Bushra Javed \\ Institute of Business Management, Karachi, Pakistan \\ Tariq Jalees \\ PAF Kiet, Karachi, Pakistan \\ Gobind M. Herani \\ Dadabhoy Institute of Higher Education, Pakistan \\ Jo-Ann Rolle \\ Dean, Business Administration, MED, The City University, New York, USA
}

\begin{abstract}
Keywords
Error management culture, innovative work behavior, organizational learning from errors and perceived psychological safety
\end{abstract}

\begin{abstract}
Errors are ubiquitous in organizational life and adversely affects organizational performance, creates negative publicity, damage organizational image and customer satisfaction. In view of its importance, we have developed a moderated mediated model to analyze the impact of organizational error management culture and organizational performance by extending error management and share cognition theory. The newly developed model was tested in the service industry of Pakistan. The sample size of the study was 300 employees with a response rate of $96 \%$. The data was collected through a web-based questionnaire. The constructs used in the study were adapted from earlier established scales and measures. Smart PLS was used to test the structural model. The results show that error management culture has a significant positive effect on organizational performance. Moreover, we found organizational learning from errors and innovative work behavior mediates the association of error management culture and organizational performance. Furthermore, we found that perceived psychological safety moderated the direct relationship between organizational learning from errors and error management culture. The current study has significant implications for management, theory, and research. For instance, perceived psychological safety in earlier studies has been used as a mediator while we have used it as a moderator. In addition, we tested multi mediation (i.e., organizational learning from errors and innovative work behaviour) to empirically validate the relationship of error management culture and organizational performance
\end{abstract}

\section{Introduction}

In many ways, the organizational landscape has undergone dramatic changes in the last two decades. The rising dynamism, and complexity of contemporary business environment couple with growing technological advancement poses new challenges and opportunities for effectively dealing with errors. Errors are rampant in every organizational life that may produce either negative or positive outcomes. Errors in organizations are defined as unintentional and potentially avertable aberrations from organizationally specific standards and goals (Frese \& Keith, 2015). With a view to its importance for organizational performance, error literature in recent years has gained momentous growth and thus regarded as a key phenomenon of burgeoning theoretical and managerial importance (Goodman et al., 2011).

Errors are prevalent in every organizational activity ranging from product development to service encounters and have certain negative ramifications such as decreased customer satisfaction, create negative publicity, damage reputation, increase economic costs, elevating psychological stress, job dissatisfaction and in extreme situation it results in loss of human life (Zhao \& Olivera, 2006). Errors are 
pervasive not only in various aspects of organizational life but also in the environment, economy and in public policy

Given the significance of errors, the organization has two complementary approaches for dealing with errors namely error prevention (error avoidance) and error management. The former approach takes errors as negative (Reason, 2000; Zhoa 2006) while the latter consider the error as valuable feedback for learning and focused on reducing the negative consequences arises from errors; Chillarege, Nordstrom, \& Williams, 2003). In other words, error management approaches view errors as constructive- that can foster positive outcomes for organizations such as learning and innovation (Lei, Naveh, \& Novikov, 2016).

In order to implement error management approaches at the organizational level, it is incumbent to established error management culture. Error management culture refers to a shared set of norms and value that facilitate error identification, communication, and rectification (Van Dyck, Frese, Baer, \& Sonnentag, 2005). Research in this area underlined the fact that error management culture is critical in reducing negative error outcomes (e.g., service interruptions, negative publicity, faulty products, lost human lives) and fostering positive error outcomes, including learning and innovation (Van Dyck et al., 2005). Learning from errors tend to produce several positive outcomes such as performance improvement (Cannon \& Edmondson, 2001 ; Heimbeck, Frese, Sonnentag, \& Keith, 2003).

Extending this line of research, organizational scholars argued that by reducing the interpersonal risks, the employees are more likely to learn from their errors (Zhan \& Hample, 2016). In this respect, a concept of perceived psychology safety -perceptions of interpersonal risky behaviours (Kahn, 1990) seemed to be an important antecedent organizational learning from errors (A. C. Edmondson, 2004)

In addition to organizational learning, error management culture may also yield new organizational innovation and processes (Cannon \& Edmondson, 2005). It is worthy to note that there is an unexpectedly very limited number of studies on the relationship between innovative work behaviour and organizational error management culture. Innovation refers to useful, creative, reliable and implementable solutions(Argote \& Miron-Spektor, 2011). Frese and Keith (2015) argued that innovation and error management culture are complementary to each other. For instance, during the process of exploration and experimentation, new types of errors are being generated experimentation (Hammond, Farr, \& Sherman, 2011). However, if the organization exhibit error management culture, then efforts are being channelized to reduce the potential damages of errors and prevent the future occurrence of similar errors (van Dyck et al., 2005).

Since error management culture encompasses organizational practices related to detection, communication, sharing and dealing with errors, it is proposed that organizational error management culture decipher into positive organizational performance through multi -mediators such as organizational learning from errors and innovative work behaviour that not only reduce negative error consequences but also increase positive outcomes of errors i.e., organizational performance. We further propose perceived psychological safety as a moderator between organizational learning from errors and organizational error management culture to

To summarize, this study aims to answer the questions of whether error management culture affects organization performance through organizational learning from errors and innovative work behaviour. In this way, this study made some valuable addition to the relevant literature. First, by focusing on intervening variables, this fills the significant research gap by delineating the relationship between error management and learning and between learning and innovation (Lei, Naveh, and Novikov 2016). Secondly, we advance our understanding that organizations that tolerate of mistakes are likely to involve in learning behaviours, and thus add to the growing literature of organizational learning. Thirdly, previous studies on organizational error management culture has been extensively conducted in high reliable organization such as aviation (Helmreich \& Merritt, 2000), medicine (Edmondson, 2004), and manufacturing (Candranegara, 2015.), however less attention has been paid to the service sector that contributes 60 to $70 \%$ to GDP in many economies(Coelho \& Augusto, 2010). Therefore, this study attempts to fill this gap by focusing on service industries in Pakistan to enhance the generalizability of the results. 


\section{Literature Review}

\subsection{Theoretical background}

Organizations are facing various types of errors (Vogus, Sutcliffe, \& Weick, 2010) . Errors are defined as the avoidable gap between expected and real state (Zhao \& Olivera, 2006). Errors may generate potential negative outcomes for organizational life which consequently hampers its performance. Therefore, the study of organizational errors merits on its own. Keeping in view the exponential growth of error literature, there is a growing interest of services scholars to investigate the impact of various dimensions of errors on the organizational performance (Guchait, Simons, \& Pasamehmetoglu, 2016)

Error management culture is defined as a shared set of organizational norms and practices to collect, communicate, handle and report error related information. Share cognition theory proposes that high error management culture facilitates employees in recognizing and managing errors timely (Fiore \& Schooler, 2004 ; Chiu, Hsu, \& Wang, 2006) . Under the error management culture, employees not only learn from their own errors but also from others, which results in effective handling errors (Mathieu, Heffner, Goodwin, Salas, \& Cannon-Bowers, 2000; Cannon \& Edmondson, 2001). Various scholars have studied the effect of organizational error management culture on employee's performance (Dimitrova, Van Dyck, Van Hooft, \& Groenewegen, 2015). Accordingly, organizations with high management culture have an active mechanism of handling and managing errors by encouraging the employees to report the errors as they happen. While in organizations that have low error management culture, the employees in such organizations are punished and blamed for committing errors (van Dyck et al. 2005). Consequently, employees tend to conceal errors to avoid negative feelings such as shame, fear, and guilt (Zhao \& Olivera, 2006).

In the same way, it was found that error management culture encouraged the employees to learn from errors and mistakes by understanding their causes or decrease the negative outcomes arises from error (Reason,2000). Furthermore, it fosters the climate of innovativeness, exploration, and experimentation via ambidexterity (Van Dyck et al. 2005); ambidexterity refers to experimenting and refining new and existing products/services that lead to better performance (Hülsheger, Anderson, \& Salgado, 2009). Therefore, we can propose that error management culture can be regarded as an important antecedent of organizational performance in the service industry.

\subsubsection{Error Management culture and Organization Learning from Errors}

Research on learning from organizational errors has gained momentum in recent years (Harteis, Bauer, \& Heid, 2012). Argyris, (1976) stated that organizational learning modified the individual behaviour ('single-loop learning') or it can also modify an individual's values and norms underlying behaviour ('double-loop learning). In order to enhance the organizational learning from errors, there must have the sound culture of accountability, inquiry (error identification, analysis, and rectification) and trust (interpersonal sharing of the error learning experience) among the employees (Ellis, Caridi, Lipshitz, \& Popper, 1999)

Van Dyck et al. (2005) suggested that there is sharp contrast between error aversion culture (avoiding and concealing errors to reduce negative feelings) and error management culture (characterized by constructive handling and communicating about errors) that encourage organization ability to learn from errors.

Argyris, (2017) argued that the process of learning comprises of identification and rectification of errors, couple with an active reflection on experience and experimentation. Moving further, learning from errors can drive transformative organizational and individual development; Tucker \& Edmondson, 2003). Previous research suggested that error management culture encourage employees to learn by allowing errors to happen (Keith \& Frese, 2011). Organizational learning is characterized as a continuous process of activities such as asking questions, pondering on results, sharing information, discussing errors, and seeking feedback (Frese \& Keith, 2015). Organizational scholars have also developed insights on various dimensions of organizational learning and their relationship with error management culture. First, organizational error management culture promotes open communication that lead to learning from errors (Van Dyck, 2000; Van Dyck et al., 2005). Second, organizational error management culture provides a secured environment for learning where employees feel safe in committing errors and talking about the errors. Third, error management cultures also incorporate mutual respect, trust and confidence among the 
employees that they will not be blamed, punished or rejected for making and discussing errors that consequently lead to learning from errors (Edmondson, 1999; Hofmann \& Frese, 2011). Based on the previous literature, the following hypothesis is proposed

H1: Organizational Error Management Culture is positively associated with organizational learning from errors

\subsubsection{Organization Learning from Errors and Innovative Work Behaviour}

Innovative work behaviour (IWB) has been defined as a set of interrelated behaviours for idea creation, idea promotion and idea realization (Janssen, 2004). There is a growing bulge of studies regarding the relationship between innovativeness and learning orientation (Sinkula, Baker, \& Noordewier, 1997). For instance, Calantone et al. (2002) empirically validating the impact of learning orientation on innovativeness. Similarly, Liu, Luo, \& Shi, (2002) also argued that organizational learning is an important predictor of firm innovativeness. In the same line, Hult et al. (2004) empirically validate the argument that organizational learning is a significant antecedent of innovativeness. According to (Cefis \& Marsili, 2005) organizational learning keeps the organization competitive by introducing new product and services. Given this line of research,(Zohoori, Mohseni, Samadi, \& Attarnezhad, 2013) established that organizational learning from errors strongly affects innovative work behaviour.

There are quite a number of few studies that empirically validate indirect relationship of organizational learning from errors with organizational performance through innovative work behaviour (Alegre \& Chiva, 2008 ; Hao, Kasper, \& Muehlbacher, 2012). Extending this line of research Škerlavaj, Song, \& Lee, (2010) conducted research on many Korean organization's innovative cultures and found that learning organization was the significant predictor of service, product and process innovation. Similarly, various scholars have studied the relationship between organizational learning from errors and innovation process ( $\mathrm{S}^{`}$ kerlavaj et al., 2010;(Park, Song, Yoon, \& Kim, 2014). So, we propose the following hypothesis

H2: Organizational learning will be positively related to Innovative work Behaviour

\subsubsection{Innovative Work Behaviour and Organization Performance}

Innovativeness is an important predictor of business performance (Cooper, 2000). Prior research on organizational performance barely focused on the organization capacity to innovate (Damanpour, 1991; Hurley \& Hult, 1998; Cooper, 2000). Innovativeness is regarded as a predominant strategic tool to promptly deal with changing internal and external environment. In the face of a complex and turbulent environment, it is crucial for an organization to fuel innovativeness for achieving high performance and competitive advantage (Hult et al., 2004).

Owing to the dynamic environment, Innovative work behaviour (IWB) of employees is pivotal in achieving better performance(Kanter, 1983). This line of research is further extended by Rosenbusch, Brinckmann, \& Bausch, (2011).They argued that innovativeness significantly contributes to overall organizational performance. Similarly, several authors also underlined the importance of innovative work behaviour to improve organizational performance (Van de Ven, 1986 ; Gatignon, Tushman, Smith, \& Anderson, 2002; Unsworth \& Parker, 2003). Moreover,Campbell, Gasser, \& Oswald, (1996) empirically demonstrated the positive link between innovative work behavior and organizational performance.

An important line of organizational performance literature also focuses on the organizational climate of innovativeness and organizational performance (Nybakk, Crespell, Hansen, \& Lunnan, 2009). Other scholars have also pointed the association of innovative work and organizational performance through gaining competitive advantage (Yuan \& Woodman, 2010 ; Shih \& Susanto, 2011; Janssen et al., 2004; Oldham \& Cummings, 1996 ; Scott \& Bruce, 1994).

H3 = Innovative Work Behaviour will be positively associated with Organizational performance

\subsubsection{Moderating role of Perceived Psychological Safety}

Psychological safety is defined as the feeling that one is investing oneself into an organizational role without fear of negative repercussion to career, status or self -image (Kahn, 1990). In other words, perceived psychological safety delineates individual perceptions of risks involved in their work environment. In prior studies, perceived psychological safety has been widely studied as mediating variable in explaining team outcomes, it is also found that perceived psychological safety play a more 
significant role as moderator (Sanner \& Bunderson, 2013). Furthermore, perceived psychological safety may turn out to moderates the antecedents of organizational performance and organizational learning (Edmondson 2004 ; Salas, Wildman, Burke, \& Goodwin, 2008 ; Sanner \& Bunderson, 2013)

A. C. Edmondson \& Lei, (2014) emphasized the role of leaders in fostering perceived psychological safety in the organization. They suggested that climate of perceived psychological safety empower employees to identify, analyse and learn the potential hazards that threaten their performance. Moreover, perceived psychological safety facilitate the employees to overcome the learning anxiety- a state where unexpected results thwart one's productive learning (Schein, 1985). Previous researches have shown that perceived psychological safety is conducive to higher performance by reducing risk in proposing a new idea, better team learning, and smoother collaboration in solving problems (West, 1990; Edmondson, 1999). Moreover, perceived psychologia cal safety was found to have key role in enhancing organizational learning from errors through experimenting and sharing past reflection (Cannon \& Edmondson, 2001; ; West \& Anderson, 1996). However, in a psychologically unsafe environment, people did not report their errors for the sake of blame and punishment. As a result, employees refused to engage in learning behaviour which ultimately dampens the organizational performance.

Error management culture on the other hand reduces the negative feelings by acknowledging the inevitableness of errors in organizational life( Lei, Naveh, Nivokov, 2016; Homsma, Van Dyck, De Gilder, Koopman, \& Elfring, 2009 ;Bauer \& Mulder, 2007; Edmondson, 1999) and thus enhances the perceived psychological safety of employees. Furthermore, perceived psychological safety was presumed to enrich organizational learning by abolishing obstacles of self-defensiveness, fear, and uncertainty (Edmondson, 1999; Sanner \& Bunderson, 2015).

Therefore, based on the above arguments we take perceived psychological safety not as a causal factor but as a moderator to strengthen the relationship between organizational error management culture and learning from errors.

H4: Perceived Psychological Safety will moderate the relationship between Error Management and Organizational learning

\subsection{Conceptual Model}

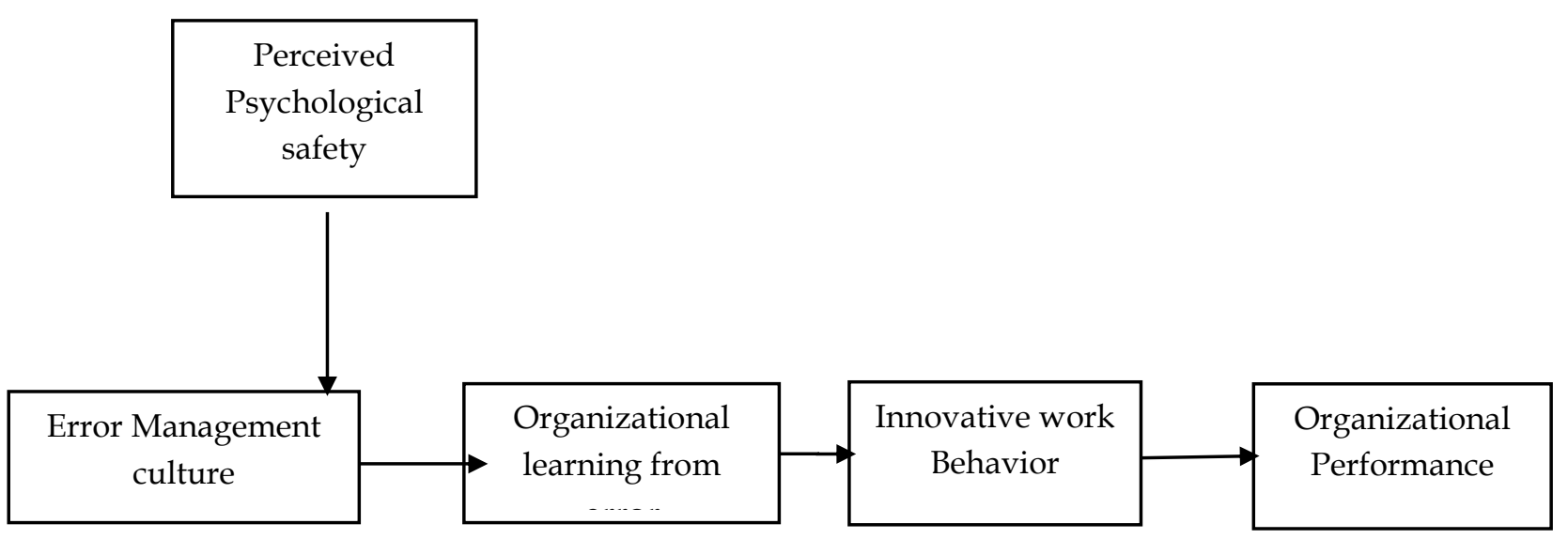

Figure 1 Conceptual Framework

\subsection{Research Methodology}

\subsubsection{Procedure and Participants}

The target audience for this paper are employees from service industries, located in Karachi. Specifically, service industries were targeted owing to limited study in this sector. First, service industries contribute 55\% to GDP of Pakistan, with annual growth rate of $4.3 \%$ and involve $35.1 \%$ of labour forces (Economic survey of Pakistan, 2015-16). Therefore, given the significance of the service sector in the economy, more studies are required to shed light on error management in services settings (Karatepe, 
2012). Second, employees working in different various sectors such as banking, marketing, medical, teaching, and management were taken to enhance the generalizability of the current study. The sample size for this study was 300 employees with responding rate of $96 \%$. The questionnaire was administered in English and was not translated into native language $U r d u$ as the target audience are well versed in comprehending English. They were informed that the research would be used for academic purpose and their confidentiality is maintained

\subsubsection{Measures \& Scale}

All the measures utilized a five-point Likert scale ( $1=$ strongly disagree; $5=$ strongly agree). The constructs used in this study was adapted from the earliest literature. For measuring, Error management culture scale, Error Orientation Questionnaire (Rybowiak, Garst, Frese, \& Batinic, 1999) with twelve-item scale was adapted. Sample items include "For us, errors are very useful for improving the work process", "After an error has occurred, it is analysed thoroughly", "When an error has occurred, we usually know how to rectify it."

To specifically assess perceived psychological safety, Edmondson,(1999) perceived psychological safety questionnaire was adapted. A sample item includes "If you make a mistake on this organization, it is often held against you", "It is safe to take a risk in this organization."

Employees rated the extent to which their organizations exhibit learning from errors, using seven items based on Putz, Schilling, Kluge, \& Stangenberg, (2013) OLE questionnaire. A sample item includes "People in our organization believe that errors at work can be a helpful part of the learning process"

To assess innovative work behaviour, a nine-item scale of Janssen (2004) has been adapted. A sample item includes "I search out new working methods or instruments to improve my work"

Organization performance has been measured using a five-item scale from Delaney \& Huselid, (1996). Sample items include "The firm has the ability to achieve a high level of customer satisfaction"

\subsubsection{Statistical Analysis}

SMART Analysis was used for statistical analysis. Prior to testing the structural model, preliminary statistical analysis was carried out which is inclusive of normality, reliability, and missing value analysis.

\section{Data Analysis and Discussion 4.1 Respondent profile}

Of the total respondents, $70.3 \%$ (211) were male while $29.7 \%$ (89) were females. Working experience of the employees varies, with $48 \%$ of the employees having 1-5 years of experience followed by $36 \%$ with 6-10 years of experience. Ages of the employees were as high as 55 and as low as 22 with $44 \%$ of the sample lie between $20-30$ years.

\subsection{Descriptive}

Univariate normality of the constructs was examined through skewness and kurtosis. Table 1 depicts the descriptive statistic.

Table 1 Descriptive Statistics

\begin{tabular}{llllll}
\hline Construct & Mean & Std. Dev & Skewness & Kurtosis & $\begin{array}{c}\text { Sronbach' } \\
\text { Alpha }\end{array}$ \\
\hline Error Management Culture & 4.08 & .234 & 1.09 & 1.04 & 0.70 \\
\hline Innovative work Behaviour & 3.85 & .440 & -.032 & 1.76 & 0.85 \\
\hline Org. Learning from Errors & 3.74 & .534 & -0.648 & 1.96 & 0.88 \\
\hline Organization Performance & 3.63 & .740 & -0.86 & 0.43 & 0.85 \\
\hline $\begin{array}{l}\text { Perceived Psychological } \\
\text { safety }\end{array}$ & 3.35 & .516 & -1.02 & 1.76 & 0.72 \\
\hline
\end{tabular}

Table 1 shows that Error Management Culture $(\mathrm{M}=4.08, \mathrm{SD}=.23)$ has the highest Skewness (-1.09) followed by Perceived Psychological Safety $(\mathrm{M}=3.35, \mathrm{SD}=.51)$, Organization Performance $(\mathrm{M}=3.63$, $\mathrm{SD}=.74)$, Organization Learning from Errors $(\mathrm{M}=3.74, \mathrm{SD}=.53)$ and Innovative Work behaviours $(\mathrm{M}=3.85$, $\mathrm{SD}=.44)$. On the other hand, the highest Kurtosis(1.96) is of Organization Learning from Errors (M=3.74, $\mathrm{SD}=.53)$ and the lowest kurtosis (.305) is of Organization performance $(\mathrm{M}=3.63, \mathrm{SD}=.74)$. All the Skewness 
and Kurtosis values ranged between \pm 2.5 indicating that the constructs have no issue with Univariate normality (Byrne, 2013).

\subsection{Construct Validity}

Construct validity is defined as the extent to which given measure adequately assess the construct it supposed to assess (Nunnally \& Bernstein, 1994)

\subsubsection{Convergent Validity}

Convergent validity in the study has been ascertained through composite reliability and average variance extracted. The results are presented in Table 2

Table 2: Convergent Validity

\begin{tabular}{lllll}
\hline Construct & Mean & Std. Dev & $\begin{array}{l}\text { Composite } \\
\text { Reliability }\end{array}$ & AVE \\
\hline Error Management Culture & 4.08 & .234 & 0.79 & 0.50 \\
\hline Innovative work Behaviour & 3.85 & .440 & 0.88 & 0.55 \\
\hline Org. Learning from Errors & 3.74 & .534 & 0.91 & 0.68 \\
\hline Organization Performance & 3.63 & .740 & 0.89 & 0.63 \\
\hline Perceived Psychological safety & 3.35 & .516 & 0.81 & 0.52 \\
\hline
\end{tabular}

The above table indicates that reliability of each construct is more than 0.7 and the variance explained for each factor is more than 0.5, which means that constructs meet the requirement of convergent validity(Bell, Bryman, \& Harley, 2018).

\subsubsection{Discriminant Validity}

Discriminant validity indicates the uniqueness and distinctiveness of the adopted construct. The results are summarized in Table 3

Table 3: Discriminant Validity

\begin{tabular}{llllll}
\hline Constructs & 1 & 2 & 3 & 4 & 5 \\
\hline Error Management Culture & 0.71 & & & & \\
\hline Innovative work Behaviour & 0.56 & 0.74 & & & \\
\hline Org. Learning from Errors & 0.53 & 0.66 & 0.82 & & \\
\hline Organization Performance & 0.38 & 0.55 & 0.49 & 0.79 & \\
\hline Perceived Psychological safety & 0.42 & 0.19 & 0.47 & 0.35 & 0.72. \\
\hline
\end{tabular}

Table 3 shows that the value of square root of AVE is higher than the square of each pair of correlation which confirms that the data fulfils the requirement of discriminant validity

\subsection{Path Coefficients}

This study has examined the direct effect as well as an indirect effect. The generated output from SMART PLS is presented in table 4 and 5 and the structural model is presented in figure 2

Table 4: Direct Effects.

\begin{tabular}{|c|c|c|c|c|c|c|}
\hline No. & Hypothesis & $\mathrm{R}^{2}$ & $\begin{array}{l}\text { Path } \\
\text { Coeff' }\end{array}$ & $\begin{array}{l}\mathrm{T} \\
\text { Statis }\end{array}$ & $\begin{array}{l}\mathrm{P} \\
\text { Values }\end{array}$ & Results \\
\hline & EMC -> Org. Learning from Errors & 0.18 & 0.20 & 6.57 & 0.00 & Accepted \\
\hline & IWB -> Organization Performance. & 0.43 & 0.54 & 21.406 & 0.00 & Accepted \\
\hline & Org. Learning from Behaviour $->$ IWB & 0.40 & 0.65 & 12.093 & 0.00 & Accepted \\
\hline & Per. Psychological safety. -> OLE & 0.30 & 0.23 & 6.67 & 0.00 & Accepted \\
\hline
\end{tabular}

$\mathrm{EMC}=$ Error Management culture, $\mathrm{OLE}=$ organizational learning from errors, IWB=Innovative Work Behaviour, Per. Psychological safety=perceived psychological safety

Hypothesis 1 was on the impact of organizational error management culture on organizational learning. The result supports the hypothesis $(\beta=0.20, t=6.57<.05)$ that organizational error management culture is positively associated with organization learning. Hypothesis 2 proposes that organization learning from errors and innovative work behaviour. The result $(\beta=0.65, \mathrm{t}=12.093<.05)$ support the hypothesis that organizational learning from errors is significantly and positively associated with 
innovative work behaviour. Hypothesis 3 was on the impact of innovative work behaviour and organizational performance. The results $(\beta=0.65, \mathrm{t}=12.093<.05)$ depict that innovative work behaviour has a significant and positive association with organizational performance. To analyse the moderating effect of perceived psychological safety on the relationship between organizational learning from errors and error management culture, we conducted moderation analyses with organizational learning from errors as the dependent variable. The results $(\beta=0.23, \mathrm{t}=6.67<.05)$ supports the hypothesis that perceived psychological safety moderates the relationship.

Table 5: Indirect Effects

\begin{tabular}{|c|c|c|c|c|c|}
\hline No. & Hypothesis & $\begin{array}{l}\text { Path } \\
\text { Coeff' }\end{array}$ & $\begin{array}{l}\mathrm{T} \\
\text { Statis }\end{array}$ & $\begin{array}{l}\mathrm{P} \\
\text { Values }\end{array}$ & Results \\
\hline & EMC -> Org. Learning from Errors-> & & & & Accepted \\
\hline & IWB & 0.13 & 2.31 & 0.01 & \\
\hline & $\begin{array}{l}\text { Per. Psy Safety } \rightarrow>\text { EMC } \rightarrow>\text { Org.l } \\
\text { Learn.Errors }\end{array}$ & 0.08 & 2.63 & 0.004 & Accepted \\
\hline & EMC -> Org.1 Learn. Errors -> IWB-> & 0.07 & 2.24 & 0.01 & Accepted \\
\hline & Org.1 Learn. Errors -> IWB -> OP & 0.36 & 9.79 & 0.00 & Accepted \\
\hline
\end{tabular}

The results revealed that both direct and indirect paths are statistically significant. Therefore, the inclusion of organizational learning from errors $(\beta=0.13, t=2.31<.05)$ and innovative work behavior $(\beta=0.36, t=9.79<.05)$ as a mediator between organizational error management culture (EMC) and organizational performance is meaningful. It can be concluded that organizational learning from errors mediates the relationship between error management culture and innovative work behavior. Furthermore, we also found that innovative work behaviour mediates the relationship between organizational learning from errors and organizational performance.



Figure 2 Measurement Model

\subsection{Discussion}

We advance our understanding of how error management culture predicts organizational performance through multi mediators i.e., organizational learning from errors and innovative work behaviour. In doing so, we integrate error management theory with share cognition theory to explain why and how organizational error management culture enhances organizational performance. Specifically, we found that error management culture inculcates learning behaviours among the employees by focusing on the informative aspect of errors. We also analysed that organizational error management culture indirectly leads to a positive organizational performance by fostering organizational learning from errors, understanding the underlying causes of errors, and preventing them from happening in the future. We also show that organizational learning from errors predicts organizational performance through 
innovative work behaviour that involves active exploration and experimentation. Moving further, we found that perceived psychological safety, reduces the anxiety related to interpersonal risks, thus encouraging employees' willingness to learn from errors

\subsection{Theoretical Contribution}

Our study extends the error literature in several ways. Although, few studies have demonstrated the positive outcome of error management culture on employee's well-being, recovery of service quality, co-worker helping behaviour and employee's performance, less attention has been paid to understand how organizational error management culture influences organizational performance via multi mediators. Thus, by theorizing and verifying organizational learning from error and innovative work behaviour as a significant intervening variable, this study creates synergies between organizational learning and organizational error management and provides supplementary support to the effectiveness of error management literature in attaining high performance. Since error management is a decisive aspect in dealing with errors in organizations, this study also reinforces the importance of error management culture in recent studies in effectively dealing with errors as compared to error prevention culture. The second worthwhile addition of this study is the inclusion of perceived psychological safety as a moderating variable. In most of the previous studies, perceived psychological safety tend to assume as an intervening variable while in this study we take it as a moderating variable. Worth noting, the result of this study suggested that perceive psychological safety served as a boundary condition influencing organizational learning from errors.

The third contribution was to analyse the impact of error management culture in the service industry. The previous error literature was taken into account the non-service industry such as manufacturing and aviation. Recent studies have begun to examine error management culture in service settings(Guchait, Zhao, Madera, Hua, \& Okumus, 2018). The current study empirically validates the significant impact of error management culture in the service industry. In this way, the current study increases the generalizability of error management literature.

\section{Practical Implications}

The current study has various practical implications. First, by analysing the impact of management culture on organizational learning from errors, this study suggests that by strengthening error management culture, the organization could make a significant difference. Secondly, many organizations have a punishment-oriented system which rewards success and punishes failure and errors. Under such type of system, employees' productivity is seriously affected since the atmosphere of the organization is not conducive for learning from errors (Tjosvold, Yu, \& Hui, 2004). In light of the given study, managers need to establish safe atmosphere rather than the blaming environment to achieve high performance. This is only done if the management understands the importance of perceived psychological safety for promoting organizational learning from errors. Moreover, management needs to develop such competencies in employees that encouraged them to think positively about errors as a part of organizational learning and innovation.

\subsection{Limitations and Direction for Future Research}

Although this study has practical significance for the service industry, but there few limitations that should be accounted for. First, there are several unexamined contextual factors that affect the rel5.1ationship between organizational error management culture and organizational performance. For instance, leadership orientation, cultural dimensions are among the few contextual factors that can affect the proposed relationship. The inclusion of contextual factors calls for answer the following questions that are under what condition might the error management interventions be more effective and how?

Secondly, there are many instances where errors are not managed for instance where speed overrule quality. In such situations, learning from errors are being stifled (Lei, 2018). So, in order to maintain the balance between the contradictory priorities (speed vs quality), future studies need to examine the complimentary priorities to influence the emergence of errors in the organization.

Thirdly, future studies should incorporate cross-cultural comparisons of error consequences, antecedents, processes to understand their underlying mechanism, (Gelfand, Frese, \& Salamon, 2011). 


\subsection{Conclusion}

Errors are ubiquitous in organizational life and it is next to impossible to eliminate all kinds of organizational errors. With the view to maintain a competitive position in the global dynamic environment, it is crucial for organizations to encourage their employees to learn and innovate from their errors. By incorporating error management literature with share cognition theory, this current study explains the underlying mechanism of organizational error management culture through multi mediators in achieving organizational performance. The result from the service industry provides the empirical support to our hypothesis that error management culture is indirectly linked to organizational performance through organizational learning from errors and innovative work behaviour and perceived psychological safety moderates the relationship between organizational learning from errors and error management culture. These findings also shed light on the importance of constructive orientation toward errors for managers to develop error management culture in their organizations.

\section{References}

Alegre, J., \& Chiva, R. (2008). Assessing the impact of organizational learning capability on product innovation performance: An empirical test. Technovation, 28(6), 315-326.

Amabile, T. M. (1988). A model of creativity and innovation in organizations. Research in Organizational Behavior, 10(1), 123-167.

Arenas, A., Tabernero, C., \& Briones, E. (2006). Effects of goal orientation, error orientation and self-efficacy on performance in an uncertain situation. Social Behavior and Personality: An International Journal, 34(5), 569586.

Argote, L., \& Miron-Spektor, E. (2011). Organizational learning: From experience to knowledge. Organization Science, 22(5), 1123-1137.

Argyris, C. (1976). Single-loop and double-loop models in research on decision making. Administrative Science Quarterly, 363-375.

Argyris, C. (2017). Integrating the Individual and the Organization. Routledge.

Bauer, J., \& Mulder, R. H. (2007). Modeling learning from errors in daily work. Learning in Health and Social Care, 6(3), 121-133.

Bell, E., Bryman, A., \& Harley, B. (2018). Business research methods. Oxford university press.

Byrne, B. M. (2013). Structural equation modeling with EQS: Basic concepts, applications, and programming. Routledge.

Campbell, J. P., Gasser, M. B., \& Oswald, F. L. (1996). The substantive nature of job performance variability. Individual Differences and Behavior in Organizations, 258, 299.

Candranegara, G. (n.d.). Conflict and error management: A case in the furniture industry. 117.

Cannon, M. D., \& Edmondson, A. C. (2001). Confronting failure: Antecedents and consequences of shared beliefs about failure in organizational work groups. Journal of Organizational Behavior: The International Journal of Industrial, Occupational and Organizational Psychology and Behavior, 22(2), 161-177.

Cannon, M. D., \& Edmondson, A. C. (2005). Failing to learn and learning to fail (intelligently): How great organizations put failure to work to innovate and improve. Long Range Planning, 38(3), 299-319.

Cefis, E., \& Marsili, O. (2005). A matter of life and death: innovation and firm survival. Industrial and Corporate Change, 14(6), 1167-1192.

Chillarege, K. A., Nordstrom, C. R., \& Williams, K. B. (2003). Learning from our mistakes: Error management training for mature learners. Journal of Business and Psychology, 17(3), 369-385.

Chiu, C.-M., Hsu, M.-H., \& Wang, E. T. (2006). Understanding knowledge sharing in virtual communities: An integration of social capital and social cognitive theories. Decision Support Systems, 42(3), 1872-1888.

Coelho, F., \& Augusto, M. (2010). Job characteristics and the creativity of frontline service employees. Journal of Service Research, 13(4), 426-438.

Cooper, R. G. (2000). Product innovation and technology strategy. Research-Technology Management, 43(1), 38-41.

Delaney, J. T., \& Huselid, M. A. (1996). The impact of human resource management practices on perceptions of organizational performance. Academy of Management Journal, 39(4), 949-969.

Dimitrova, N. G., Van Dyck, C., Van Hooft, E. A., \& Groenewegen, P. (2015). Don't Fuss, Focus: The Mediating Effect of On-Task Thoughts on the Relationship between Error Approach Instructions and Task Performance. Applied Psychology, 64(3), 599-624.

Edmondson, A. (1999). Psychological Safety and Learning Behavior in Work Teams. Administrative Science Quarterly, 44(2), 350. https://doi.org/10.2307/2666999

Edmondson, A. C. (2004). Learning from mistakes is easier said than done: Group and organizational influences on the detection and correction of human error. The Journal of Applied Behavioral Science, 40(1), 66-90. 
Edmondson, A. C., \& Lei, Z. (2014). Psychological safety: The history, renaissance, and future of an interpersonal construct. Annu. Rev. Organ. Psychol. Organ. Behav., 1(1), 23-43.

Ellis, S., Caridi, O., Lipshitz, R., \& Popper, M. (1999). Perceived error criticality and organizational learning: an empirical investigation. Knowledge and Process Management, 6(3), 166-175.

Fiore, S. M., \& Schooler, J. W. (2004). Process mapping and shared cognition: Teamwork and the development of shared problem models. Team Cognition: Understanding the Factors That Drive Process and Performance, 133-152.

Frese, M., \& Keith, N. (2015). Action errors, error management, and learning in organizations. Annual Review of Psychology, 66, 661-687.

Gatignon, H., Tushman, M. L., Smith, W., \& Anderson, P. (2002). A structural approach to assessing innovation: Construct development of innovation locus, type, and characteristics. Management Science, 48(9), 1103-1122.

Gelfand, M. J., Frese, M., \& Salamon, E. (2011). Cultural influences on error prevention, detection, and management. Errors in Organizations, 273315.

Goodman, P. S., Ramanujam, R., Carroll, J. S., Edmondson, A. C., Hofmann, D. A., \& Sutcliffe, K. M. (2011). Organizational errors: Directions for future research. Research in Organizational Behavior, 31, 151-176.

Guchait, P., Simons, T., \& Pasamehmetoglu, A. (2016). Error recovery performance: the impact of leader behavioral integrity and job satisfaction. Cornell Hospitality Quarterly, 57(2), 150-161.

Guchait, P., Zhao, X., Madera, J., Hua, N., \& Okumus, F. (2018). Can error management culture increase work engagement in hotels? The moderating role of gender. Service Business, 12(4), 757-778.

Hammond, M. M., Farr, J. L., \& Sherman, P. O. (2011). The role of errors in the creative and innovative process. Errors in Organizations, 67-96.

Hao, Q., Kasper, H., \& Muehlbacher, J. (2012). How does organizational structure influence performance through learning and innovation in Austria and China? Chinese Management Studies, 6(1), 36-52.

Harteis, C., Bauer, J., \& Heid, H. (2012). Research on human fallibility and learning from errors at work: Challenges for theory, research, and practice. In Human Fallibility (pp. 255-265). Springer.

Heimbeck, D., Frese, M., Sonnentag, S., \& Keith, N. (2003). Integrating errors into the training process: The function of error management instructions and the role of goal orientation. Personnel Psychology, 56(2), 333-361.

Helmreich, R. L., \& Merritt, A. C. (2000). Safety and error management: The role of Crew Resource Management. 11.

Hofmann, D. A., \& Frese, M. (2011). Error in organizations. Routledge.

Homsma, G. J., Van Dyck, C., De Gilder, D., Koopman, P. L., \& Elfring, T. (2009). Learning from error: The influence of error incident characteristics. Journal of Business Research, 62(1), 115-122.

Hülsheger, U. R., Anderson, N., \& Salgado, J. F. (2009). Team-level predictors of innovation at work: a comprehensive meta-analysis spanning three decades of research. Journal of Applied Psychology, 94(5), 1128.

Janssen, O. (2004). How fairness perceptions make innovative behavior more or less stressful. Journal of Organizational Behavior, 25(2), 201-215.

Kahn, W. A. (1990). Psychological conditions of personal engagement and disengagement at work. Academy of Management Journal, 33(4), 692-724.

Kanter, R. M. (1983). The change masters: innovation for productivity in the American mode. Simon and schuster.

Karatepe, O. M. (2012). Perceived organizational support, career satisfaction, and performance outcomes: a study of hotel employees in Cameroon. International Journal of Contemporary Hospitality Management, 24(5), 735-752.

Keith, N., \& Frese, M. (2011). Enhancing Firm Performance and Innovativeness Through Error Management Culture. In the Handbook of Organizational Culture and Climate (pp. 137-157).

https://doi.org/10.4135/9781483307961.n9

Lei, Z., Naveh, E., \& Novikov, Z. (2016). Errors in Organizations: An Integrative Review via Level of Analysis, Temporal Dynamism, and Priority Lenses. Journal of Management, 42(5), 1315-1343. https:// doi.org/10.1177/0149206316633745

Liu, S. S., Luo, X., \& Shi, Y.-Z. (2002). Integrating customer orientation, corporate entrepreneurship, and learning orientation in organizations-in-transition: an empirical study. International Journal of Research in Marketing, 19(4), 367-382. https:/ / doi.org/10.1016/S0167-8116(02)00098-8

Mathieu, J. E., Heffner, T. S., Goodwin, G. F., Salas, E., \& Cannon-Bowers, J. A. (2000). The influence of shared mental models on team process and performance. Journal of Applied Psychology, 85(2), 273.

Nunnally, J. C., \& Bernstein, I. H. (1994). Validity. Psychometric Theory, 3, 99-132.

Nybakk, E., Crespell, P., Hansen, E., \& Lunnan, A. (2009). Antecedents to forest owner innovativeness: An investigation of the non-timber forest products and services sector. Forest Ecology and Management, 257(2), 608-618.

Oldham, G. R., \& Cummings, A. (1996). Employee creativity: Personal and contextual factors at work. Academy of Management Journal, 39(3), 607-634. 
Park, Y. K., Song, J. H., Yoon, S. W., \& Kim, J. (2014). Learning organization and innovative behavior: The mediating effect of work engagement. European Journal of Training and Development, 38(1/2), 75-94.

Popper, M., \& Lipshitz, R. (2000). Organizational learning: Mechanisms, culture, and feasibility. Management Learning, 31(2), 181-196.

Putz, D., Schilling, J., Kluge, A., \& Stangenberg, C. (2013). Measuring organizational learning from errors: Development and validation of an integrated model and questionnaire. Management Learning, 44(5), 511-536.

Reason, J. (2000). Human error: models and management. Bmj, 320(7237), 768-770.

Rosenbusch, N., Brinckmann, J., \& Bausch, A. (2011). Is innovation always beneficial? A meta-analysis of the relationship between innovation and performance in SMEs. Journal of Business Venturing, 26(4), 441-457.

Rybowiak, V., Garst, H., Frese, M., \& Batinic, B. (1999). Error orientation questionnaire (EOQ): Reliability, validity, and different language equivalence. Journal of Organizational Behavior: The International Journal of Industrial, Occupational and Organizational Psychology and Behavior, 20(4), 527-547.

Salas, E., Wildman, J. L., Burke, C. S., \& Goodwin, G. F. (2008). Team effectiveness in complex organizations: An overview. In Team Effectiveness in Complex Organizations (pp. 37-50). Routledge.

Sanner, B., \& Bunderson, J. S. (2013). Psychological safety, learning, and performance: A comparison of direct and contingent effects. Academy of Management Proceedings, 2013, 10198. Academy of Management Briarcliff Manor, NY 10510.

Sanner, B., \& Bunderson, J. S. (2015). When feeling safe isn't enough: Contextualizing models of safety and learning in teams. Organizational Psychology Review, 5(3), 224-243.

Schein, E. H. (1985). Defining organizational culture. Classics of Organization Theory, 3, 490-502.

Scott, S. G., \& Bruce, R. A. (1994). Determinants of innovative behavior: A path model of individual innovation in the workplace. Academy of Management Journal, 37(3), 580-607.

Shih, H.-A., \& Susanto, E. (2011). Is innovative behavior really good for the firm? Innovative work behavior, conflict with coworkers and turnover intention: Moderating roles of perceived distributive fairness. International Journal of Conflict Management, 22(2), 111-130.

Sinkula, J. M., Baker, W. E., \& Noordewier, T. (1997). A framework for market-based organizational learning: Linking values, knowledge, and behavior. Journal of the Academy of Marketing Science, 25(4), 305.

Škerlavaj, M., Song, J. H., \& Lee, Y. (2010). Organizational learning culture, innovative culture, and innovations in South Korean firms. Expert Systems with Applications, 37(9), 6390-6403.

Tjosvold, D., Yu, Z., \& Hui, C. (2004). Team learning from mistakes: the contribution of cooperative goals and problem-solving. Journal of Management Studies, 41(7), 1223-1245.

Tucker, A. L., \& Edmondson, A. C. (2003). Why hospitals don't learn from failures: Organizational and psychological dynamics that inhibit system change. California Management Review, 45(2), 55-72.

Unsworth, K. L., \& Parker, S. K. (2003). Proactivity and innovation: Promoting a new workforce for the new workplace. The New Workplace: A Guide to the Human Impact of Modern Working Practices, 175-196.

Ussahawanitchakit, P. (2008). Impacts of organizational learning on innovation orientation and firm efficiency: an empirical assessment of accounting firms in Thailand. International Journal of Business Research, 8(4), 1-12.

Van de Ven, A. H. (1986). Central problems in the management of innovation. Management Science, 32(5), 590-607.

Van Dyck, C., Frese, M., Baer, M., \& Sonnentag, S. (2005). Organizational error management culture and its impact on performance: a two-study replication. Journal of Applied Psychology, 90(6), 1228.

Vogus, T. J., Sutcliffe, K. M., \& Weick, K. E. (2010). Doing no harm: enabling, enacting, and elaborating a culture of safety in health care. Academy of Management Perspectives, 24(4), 60-77.

West, M. A., \& Anderson, N. R. (1996). Innovation in top management teams. Journal of Applied Psychology, 81(6), 680 .

Yuan, F., \& Woodman, R. W. (2010). Innovative behavior in the workplace: The role of performance and image outcome expectations. Academy of Management Journal, 53(2), 323-342.

Zhan, M., \& Hample, D. (2016). Predicting employee dissent expression in organizations: A cost and benefits approach. Management Communication Quarterly, 30(4), 441-471.

Zhao, B., \& Olivera, F. (2006). Error Reporting in Organizations. Academy of Management Review, 31(4), $1012-1030$. https://doi.org/10.5465/amr.2006.22528167

Zohoori, M., Mohseni, S., Samadi, B., \& Attarnezhad, O. (2013). The relationship between knowledge sharing and innovation in understand their electronic industry of Iran. Journal of Small Business and Entrepreneurship Development, 1(1), 26-33. 